$* *+* * * * * *$

SHALEXENVIRONMENT

SHALEXENVIRONORTIUM
[ $\gg$ COnCEPT]

\title{
Optimal Shale Gas Flowback Water Desalination under Correlated Data Uncertainty
}

Viviani C. Onishi, Rubén Ruiz-Femenia, Raquel Salcedo-Díaz, Alba Carrero-Parreño,

Juan A. Reyes-Labarta, José A. Caballero

Institute of Chemical Process Engineering, University of Alicante 


\section{Presentation overview}

What is we going to present here?

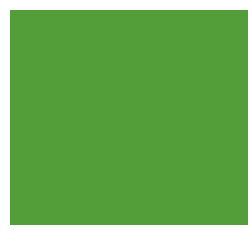

Motivation

Introduction

Stochastic multiscenario model

Mathematical model \& Scenarios generation

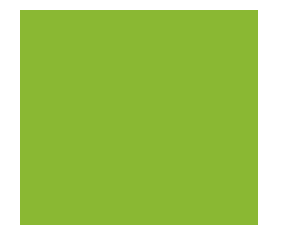

Problem Statement

ZLD desalination under uncertainty

Process Description

Superstructure

\section{Conclussions}

Case study

Shale gas wastewater desalination 


\section{Motivation}

Introduction

- Shale gas hydraulic fracturing demands large amounts of water, on average $\mathbf{9 0 0 0 - 2 9 0 0 0 ~ m 3 ~ o f ~ w a t e r ~ t o ~}$ complete each well (Yang el al. 2014). (10\% used in drilling and 90\% in hydraulic fracturing).

- A fraction of the water used for drilling and hydraulic fracture return to the surface (between $10 \%$ and $70 \%$ ) with typical values around $35 \%$.

- Consequently, high volumes of wastewater from shale gas well pads are generated. As an example, a production forecast for the Marcellus play suggests that Pennsylvania will generate over half billion cubic feet per year by 2025 (Gay et al. 2012)

- Most of the water returns to the surface in the first two weeks -flowback water- then it tends to stabilize and continues producing water during the whole life of the well -produced water-.

- The flowback water include part of the additives included in the hydraulic fracturing fluid: Proppant (sand); Friction reducers; surfactants, scale inhibitors, Biocide, etc. And other compounds depending on the geological characteristics of the shale. 


\section{Motivation}

Typical range of concentrations for some common constituents of flowback/produced water from natural gas development in the Marcellus shale.

(Data compiled by Elise Barbot, University of Pittsburgh, and Juan Peng, Carnegie Mellon University.)

\begin{tabular}{|c|c|c|c|}
\hline Constituent & Low (mg/l) & Medium (mg/l) & High (mg/l) \\
\hline Total dissolved solids & 66000 & 150000 & 261000 \\
\hline Total suspended solids & 27 & 380 & 3200 \\
\hline Hardness (as $\mathrm{CaCO}_{3}$ ) & 9100 & 29000 & 55000 \\
\hline Alkalinity (as $\mathrm{CaCO}_{3}$ ) & 200 & 200 & 1100 \\
\hline Chloride & 32000 & 76000 & 148000 \\
\hline Sulfate & Not Detected & 7 & 500 \\
\hline Sodium & 18000 & 33000 & 44000 \\
\hline Calcium, total & 3000 & 9800 & 31000 \\
\hline Strontium, total & 1400 & 2100 & 6800 \\
\hline Barium, total & 2300 & 3300 & 4700 \\
\hline Bromide & 720 & 1200 & 1600 \\
\hline Iron, total & 25 & 48 & 55 \\
\hline Manganese, total & 3 & 7 & 7 \\
\hline Oil and grease & 10 & 18 & 260 \\
\hline Total radioactivity & Not Detected & Not Detected & Not Detected \\
\hline
\end{tabular}

This project has received funding from the European 


\section{Motivation}

Introduction

Salinity of the flowback waters from various shales expressed in terms of Total Dissolved Solids (TDS).

\begin{tabular}{|l|l|l|}
\hline Shale & Average TDS, ppm & Maximum TDS, ppm \\
\hline Fayetteville & 13,000 & 20,000 \\
\hline Wooford & 30,000 & 40,000 \\
\hline Barnett & 80,000 & $>150,000$ \\
\hline Marcellus & 120,000 & $>280,000$ \\
\hline Haynesville & 110,000 & $>200,000$ \\
\hline Lebien & $\sim 16,000-70,000 *$ & \\
\hline Lubocino & $\sim 17,000 *$ & \\
\hline
\end{tabular}

* Estimated by correlation with other parameters. 


\section{Motivation}

Introduction

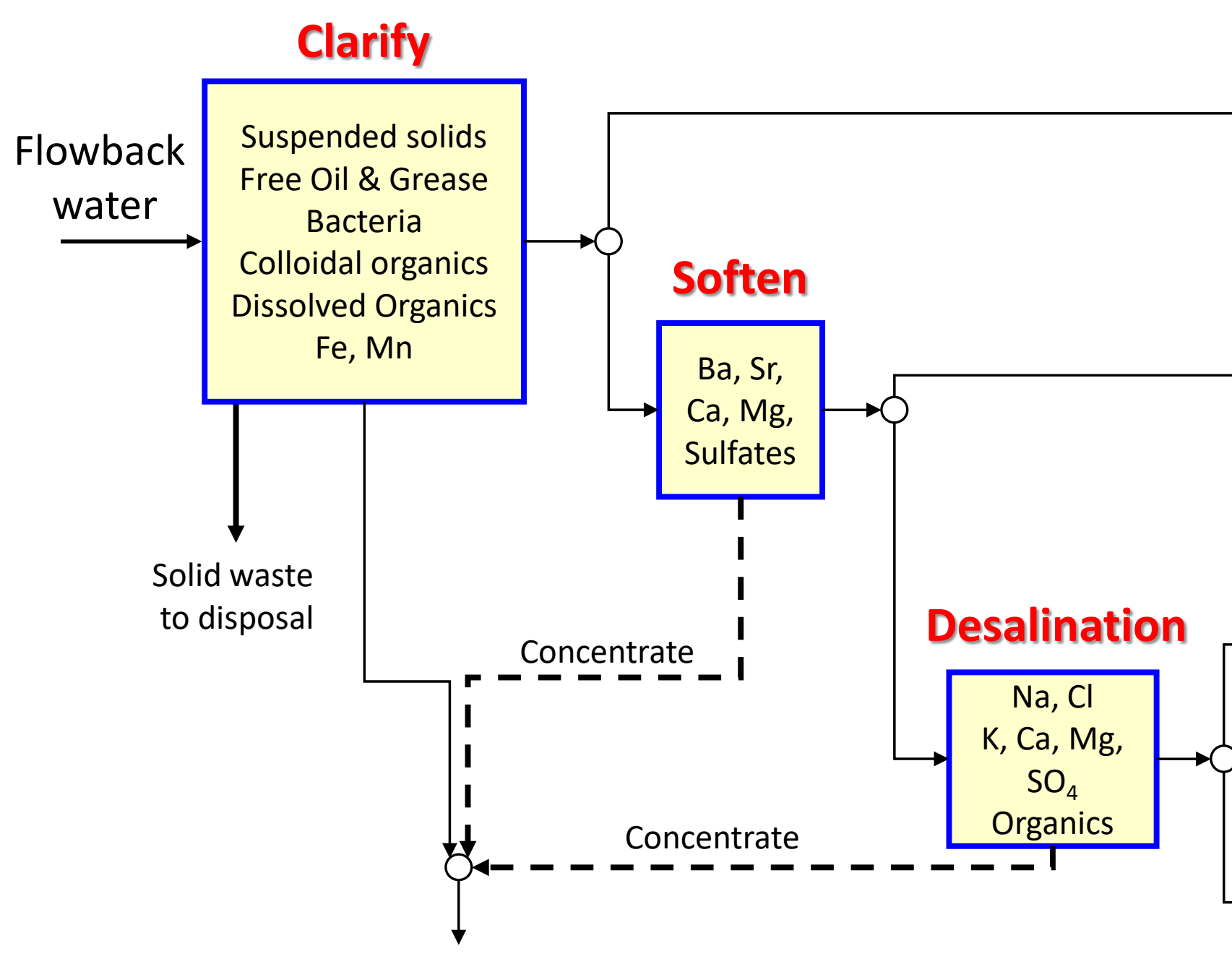

Product options

Clarify

To disposal
Product -1

Clarified only

(for frac re-use)

Product -2

Softened

(for frac re-use)

Product -3

Desalinated

(for frac re-use)

Product -4

$<500$ ppm TDS

(for surface discharge) 


\section{Motivation}

Introduction

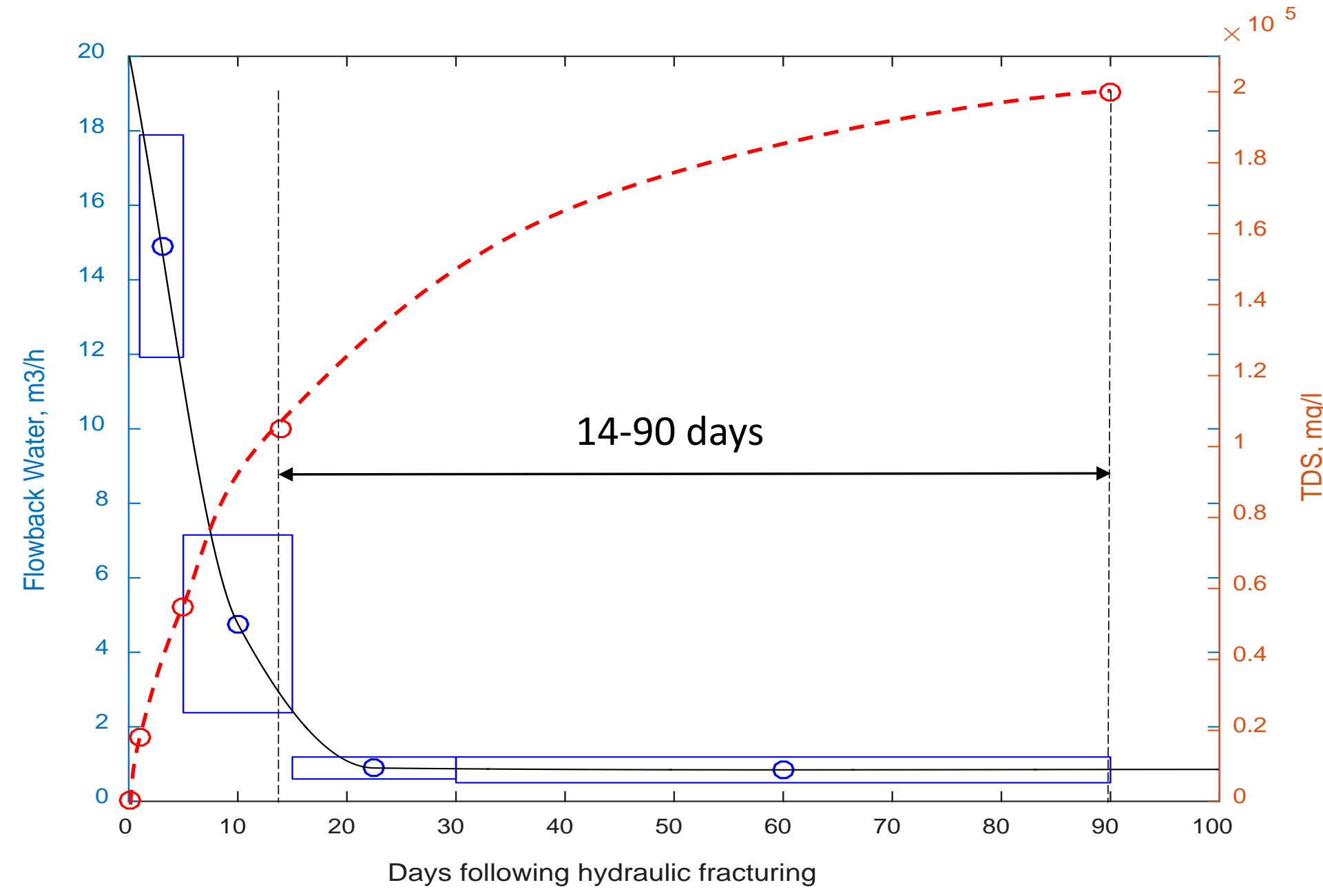

Uncertainty on both: Water flowrate and concentration 


\section{Motivation}

- To address these issues, we introduce a two stage stochastic model for the robust design of ZLD desalination systems under uncertainty

- In this new approach, wastewater salinity and flowrate are both treated as uncertain design parameters: The uncertainty is mainly related to the great variability presented in well data from real shale plays

- To the best of our knowledge, this is the first study assessing the impacts of data uncertainty on the optimal design of ZLD evaporation systems, specially developed for high-salinity shale gas wastewater

- Also, important improvements on the MEE-MVC process are implemented, including the use of an external energy source to avoid oversized equipment and the consideration of variable compressor efficiency that allows obtaining a more precise and robust operating performance 


\section{Problem statement}

- Given is a high-salinity stream of shale gas wastewater, with known inlet state (described by temperature, and mean values for salt concentration and flowrate) and target condition defined by the ZLD specification

- Furthermore, desalination system and energy services (steam and electricity) are also provided with their corresponding costs

- Salt concentration and flowrate of the inlet water stream are both considered as uncertain design parameters that can be explicitly expressed through a set of correlated feeding scenarios with given probability of occurrence

The new stochastic modelling approach is aimed at obtaining a robust design of MEE-MVC desalination systems by reducing brine discharges and energy consumption, while accounting for different feeding scenarios. The MEE-MVC system should be able to efficiently operate at ZLD condition in a large range of correlated feeding scenarios 


\section{Process description}

Superstructure

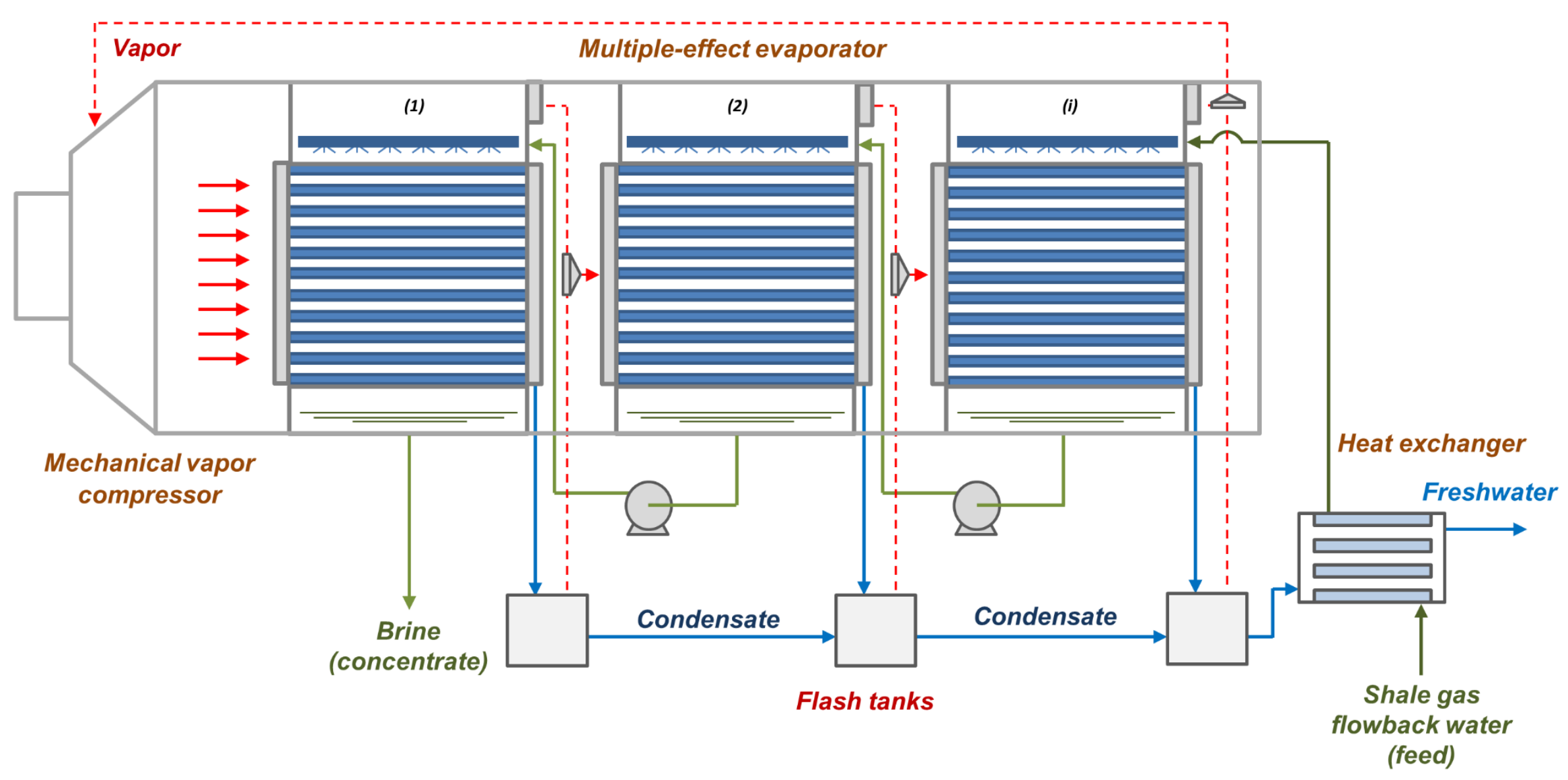

Figure 1. General superstructure proposed for the MEE-MVR desalination plant of wastewater from shale gas production

$[\gg$ COnCEPT]

Computer Optimization
in Chemical nnineering
Processes and Technologeses 


\section{Two stage stochastic model}

Mathematical modelling approach

- Sizing equations for all equipment

- Mass and energy balances

- Temperature and pressure feasibilities

- Design constraints (ZLD operation)

- Objective function

Index sets

$$
\begin{aligned}
& I=\{i / i=1,2, \ldots, I \text { is an evaporation effect }\} \\
& S=\{s / s=1,2, \ldots, S \text { is a feeding scenario }\}
\end{aligned}
$$

Decision variables

- First stage (here and now): sizing-related variables (e.g., volumes, and heat transfer areas)

- Second stage (wait and see): all remaining optimization variables
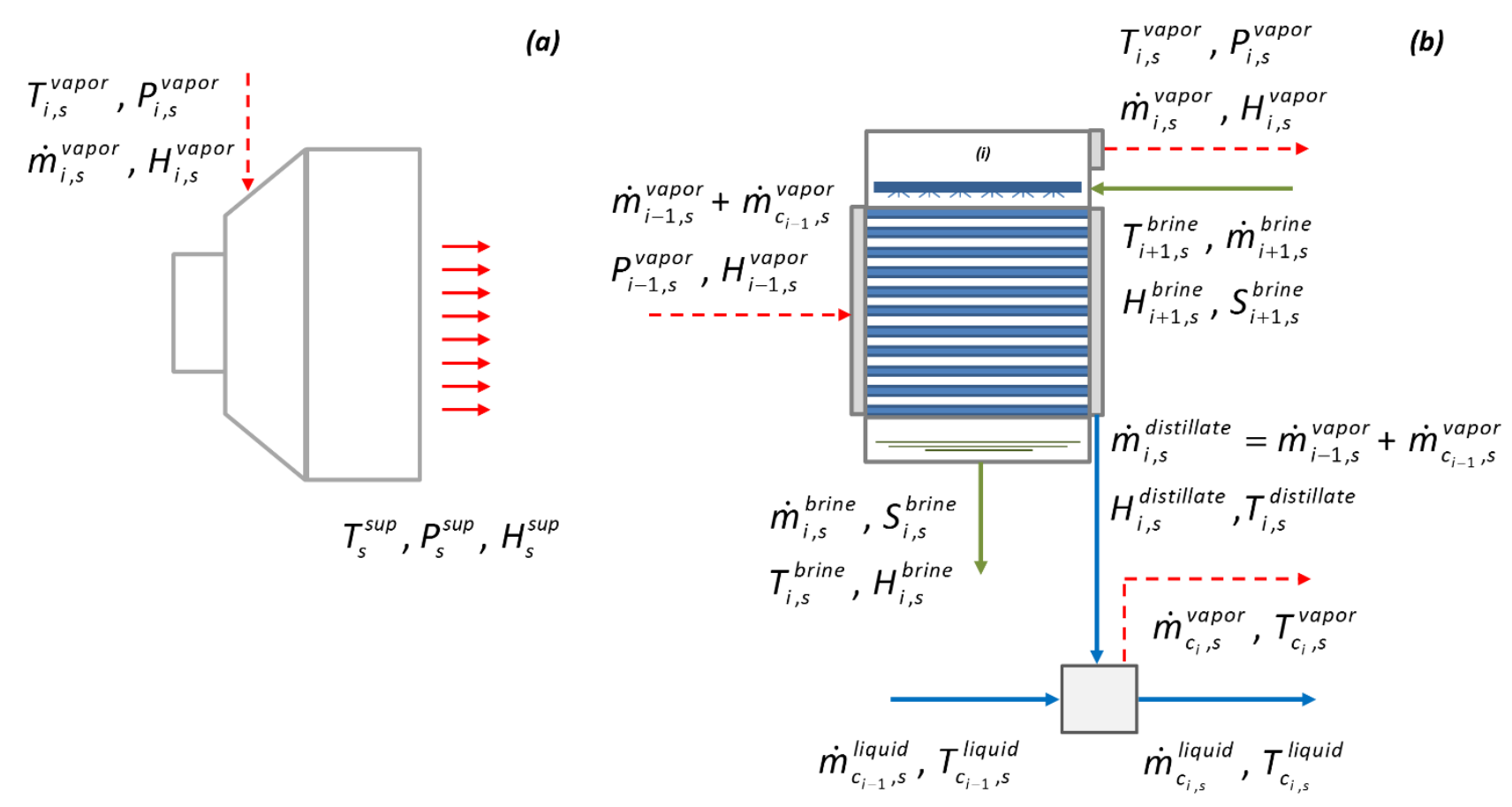

Figure 2. Decision variables for the optimization of: $(a)$ single-stage compressor; and, $(b)$ effect $i$ of the horizontal falling film evaporator coupled to flashing tank $i$ in the MEE-MVR system 


\section{Two stage stochastic model}

Mathematical modelling approach

\section{Design of the multiple-effect evaporator}

\section{Mass balances}

Evaporator effect $i$ :

$$
\begin{array}{ll}
\dot{m}_{i+1, s}^{\text {brine }}=\dot{m}_{i, s}^{\text {brine }}+\dot{m}_{i, s}^{\text {vapor }} & \forall 1 \leq i \leq I-1, \forall s \in S \\
\dot{m}_{i+1, s}^{\text {brine }} \cdot S_{i+1, s}^{\text {brine }}=\dot{m}_{i, s}^{\text {brine }} \cdot S_{i, s}^{\text {brine }} & \forall 1 \leq i \leq I-1, \forall s \in S
\end{array}
$$

First effect:

$$
\begin{aligned}
& \tilde{m}_{i n, s}^{\text {feed }}=\dot{m}_{i, s}^{\text {brine }}+\dot{m}_{i, s}^{\text {vapor }} \quad \forall i=I, \forall s \in S \\
& \tilde{m}_{i n, s}^{\text {feed }} \cdot \tilde{S}_{i n, s}^{\text {feed }}=\dot{m}_{i, s}^{\text {brine }} \cdot S_{i, s}^{\text {brine }} \quad \forall i=I, \forall s \in S
\end{aligned}
$$

$\left.\tilde{m}_{i n, s}^{\text {feed }}\right\}$ are the stochastic parameters that define $\left.\tilde{S}_{i n, s}^{\text {feed }}\right\}$ flowrate and salinity for the feed water in the set of distinct scenarios 


\section{Two stage stochastic model}

Mathematical modelling approach

\section{Design of the multiple-effect evaporator}

\section{Global energy balances}

specific enthalpies are estimated at the

$Q_{i, s}+\dot{m}_{i+1, s}^{\text {brine }} \cdot H_{i+1, s}^{\text {brine }}=\dot{m}_{i, s}^{\text {brine }} \cdot H_{i, s}^{\text {brine }}+\dot{m}_{i, s}^{\text {vapor }} \cdot H_{i, s}^{\text {vapor }} \quad \forall i<I, \forall s \in S$ same boiling point temperature

$Q_{i, s}+\tilde{m}_{i n, s}^{\text {feed }} \cdot H_{i, s}^{\text {feed }}=\dot{m}_{i, s}^{\text {brine }} \cdot H_{i, s}^{\text {brine }}+\dot{m}_{i, s}^{\text {vapor }} \cdot H_{i, s}^{\text {vapor }} \quad \forall i=I, \forall s \in S$

\section{Boiling point temperature}

$$
\begin{aligned}
T_{i, s}^{\text {boiling }} & =T_{i, s}^{\text {ideal }}+B P E_{i, s} \quad \forall i \in I, \forall s \in S \\
B P E_{i, s} & =\left[\begin{array}{l}
0.1581+2.769 \cdot\left(X_{i, s}^{\text {salt }}\right)-0.002676 \cdot\left(T_{i, s}^{\text {ideal }}\right) \\
+41.78\left(X_{i, s}^{\text {salt }}\right)^{0.5}+0.134 \cdot\left(X_{i, s}^{\text {salt }} \cdot T_{i, s}^{\text {ideal }}\right)
\end{array}\right] \quad \forall i \in I, \forall s \in S
\end{aligned}
$$

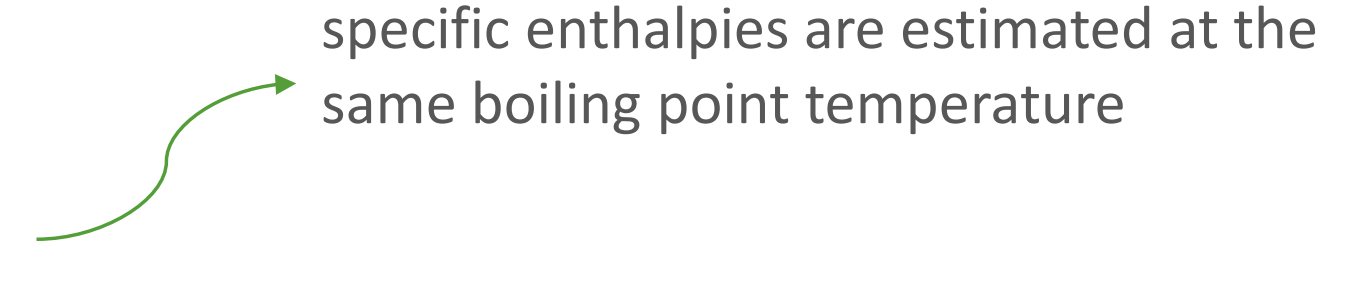




\section{Two stage stochastic model}

Mathematical modelling approach

Design of the multiple-effect evaporator

4. Energy requirements

$$
\begin{aligned}
& Q_{i, s}=\dot{m}_{s}^{\text {sup }} \cdot C p_{i, s}^{\text {vapor }} \cdot\left(T_{s}^{\text {sup }}-T_{i, s}^{\text {condensate }}\right)+\dot{m}_{s}^{\text {sup }} \cdot\left(H_{i, s}^{\text {cv }}-H_{i, s}^{\text {condensate }}\right)+Q_{s}^{\text {external }} \quad \forall i=1, \forall s \in S \\
& Q_{i, s}=\left(\dot{m}_{i-1, s}^{\text {vapor }}+\dot{m}_{c_{i-1, s}}^{\text {vapor }}\right) \cdot \lambda_{i, s} \quad \forall i>1, \forall s \in S
\end{aligned}
$$

In which,

$$
Q_{s}^{\text {external }}=\dot{m}_{s}^{\text {steam }} \cdot C p_{s}^{\text {vapor }} \cdot\left(T_{s}^{\text {steam }}-T_{i, s}^{\text {condensate }}\right)+\dot{m}_{s}^{\text {steam }} \cdot\left(H_{i, s}^{c v}-H_{i, s}^{\text {condensate }}\right) \quad \forall i=1, \forall s \in S
$$

energy amount from the external source

(steam) used to avoid oversized equipment 


\section{Two stage stochastic model}

Mathematical modelling approach

Design of the multiple-effect evaporator

5. Heat transfer area

$A^{\text {evaporator }}=\sum_{i=1}^{I} A_{i}$

Overall heat transfer coefficient:

In which,

$$
U_{i, s}=0.001 \cdot\left[\begin{array}{l}
1939.4+1.40562 \cdot\left(T_{i, s}^{\text {boiling }}\right) \\
-0.00207525 \cdot\left(T_{i, s}^{\text {boiling }}\right)^{2}+0.0023186 \cdot\left(T_{i, s}^{\text {boiling }}\right)^{3}
\end{array}\right]
$$

Log mean temperature difference :

$$
\begin{aligned}
& A_{i} \geq\left[\begin{array}{l}
\dot{m}_{s}^{\text {sup }} \cdot C p_{i, s}^{\text {vapor }} \cdot\left(T_{s}^{\text {sup }}-T_{i, s}^{\text {condensate }}\right) /\left(U^{S} \cdot \operatorname{LMTD}_{i, s}\right) \\
+\dot{m}_{s}^{\text {sup }} \cdot\left(H_{i, s}^{c v}-H_{i, s}^{\text {condensate }}\right) / U_{i, s} \cdot\left(T_{i, s}^{\text {condensate }}-T_{i, s}^{\text {boiling }}\right)
\end{array}\right] \\
& A_{i} \geq Q_{i, s} /\left(U_{i, s} \cdot L M T D_{i, s}\right) \quad \forall i>1, \forall s \in S
\end{aligned}
$$$$
\forall i=1, \forall s \in S
$$

$$
\begin{gathered}
\operatorname{LMTD}_{i, s}=\left[0.5 \cdot\left(\theta_{1 i, s} \cdot \theta_{2 i, s}\right) \cdot\left(\theta_{1 i, s}+\theta_{2 i, s}\right)\right]^{\frac{1}{3}} \quad \forall i \in I, \forall s \in S \\
\theta_{1 i, s}=\left\{\begin{array}{ll}
T_{s}^{\text {sup }}-T_{i, s}^{\text {boiling }} & \forall i=1, \forall s \in S \\
T_{i, s}^{\text {sat }}-T_{i, s}^{\text {boiling }} & \forall i>1, \forall s \in S
\end{array}\right. \text { and } \\
\theta_{2 i, s}= \begin{cases}T_{i, s}^{\text {condensate }}-T_{i+1, s}^{\text {boiling }} & \forall i=1, \forall s \in S \\
T_{i, s}^{\text {sat }}-T_{i+1, s}^{\text {boiling }} & \forall 1<i<I, \forall s \in S \\
T_{i, s}^{\text {sat }}-T_{i, s}^{\text {feed }} & \forall i=I, \forall s \in S\end{cases}
\end{gathered}
$$




\section{Two stage stochastic model}

Mathematical modelling approach

\section{Design of the multiple-effect evaporator}

6. Pressure feasibility

$$
P_{i, s}^{\text {vapor }} \geq P_{i+1, s}^{\text {vapor }}+\Delta P_{\min } \quad \forall i<I, \forall s \in S
$$

7. Constraints on temperature

$$
\begin{array}{llll}
T_{s}^{\text {sup }} \geq T_{i, s}^{\text {condensate }}+\Delta T_{\text {min }}^{1} & \forall i=1, \forall s \in S & T_{i, s}^{\text {condensate }} \geq T_{i+1, s}^{\text {boiling }}+\Delta T_{\text {min }}^{3} & \forall i<I, \forall s \in S \\
T_{i-1, s}^{\text {boiling }} \geq T_{i, s}^{\text {condensate }}+\Delta T_{\text {min }}^{1} & \forall i>1, \forall s \in S & T_{i, s}^{\text {condensate }} \geq T_{i, s}^{\text {feed }}+\Delta T_{\text {min }}^{3} & \forall i=I, \forall s \in S \\
T_{i, s}^{\text {boiling }} \geq T_{i+1, s}^{\text {boiling }}+\Delta T_{\text {min }}^{2} & \forall i<I, \forall s \in S & T_{i, s}^{\text {condensate }} \geq T_{i, s}^{\text {boiling }}+\Delta T_{\text {min }}^{4} & \forall i \in I, \forall s \in S \\
T_{i, s}^{\text {boiling }} \geq T_{i, s}^{\text {feed }}+\Delta T_{\text {min }}^{2} & \forall i=I, \forall s \in S & T_{i, s}^{\text {sat }} \geq T_{i, s}^{\text {boiling }}+\Delta T_{\text {min }}^{4} & \forall i \in I, \forall s \in S
\end{array}
$$

$\begin{array}{llll}T_{s}^{\text {sup }} \geq T_{i, s}^{\text {condensate }}+\Delta T_{\text {min }}^{1} & \forall i=1, \forall s \in S & T_{i, s}^{\text {condensate }} \geq T_{i+1, s}^{\text {boiling }}+\Delta T_{\text {min }}^{3} & \forall i<I, \forall s \in S \\ T_{i-1, s}^{\text {boiling }} \geq T_{i, s}^{\text {condensate }}+\Delta T_{\text {min }}^{1} & \forall i>1, \forall s \in S & T_{i, s}^{\text {condensate }} \geq T_{i, s}^{\text {feed }}+\Delta T_{\text {min }}^{3} & \forall i=I, \forall s \in S \\ T_{i, s}^{\text {boiling }} \geq T_{i+1, s}^{\text {boiling }}+\Delta T_{\text {min }}^{2} & \forall i<I, \forall s \in S & T_{i, s}^{\text {condensate }} \geq T_{i, s}^{\text {boiling }}+\Delta T_{\text {min }}^{4} & \forall i \in I, \forall s \in S \\ T_{i, s}^{\text {boiling }} \geq T_{i, s}^{\text {feed }}+\Delta T_{\text {min }}^{2} & \forall i=I, \forall s \in S & T_{i, s}^{\text {sat }} \geq T_{i, s}^{\text {boiling }}+\Delta T_{\text {min }}^{4} & \forall i \in I, \forall s \in S\end{array}$




\section{Two stage stochastic model}

Mathematical modelling approach

Design of the mechanical vapor compressor

1. Isentropic temperature

$T_{s}^{i s}=\left(T_{i, s}^{\text {mix }}+273.15\right) \cdot\left(P_{s}^{\text {sup }} / P_{i, s}^{\text {vapor }}\right)^{\frac{\gamma-1}{\gamma}}-273.15 \quad \forall i=I, \forall s \in S$

In which,

$P_{s}^{\text {sup }} \leq C R_{\max } \cdot P_{i, s}^{\text {vapor }} \quad \forall i=I, \forall s \in S$

2. Superheated vapor temperature

$$
T_{s}^{s u p}=T_{i, s}^{m i x}+\frac{1}{\eta_{s}} \cdot\left(T_{s}^{i s}-T_{i, s}^{m i x}\right) \quad \forall i=I, \forall s \in S
$$

isentropic efficiency

\section{Isentropic efficiency}

$\eta_{s}=(0.35 / 0.8) \cdot\left(\frac{W_{s}}{W C}-0.2\right)+0.5 \quad \forall s \in S$

In which,

$$
W C \geq W_{s} \quad \forall s \in S
$$

These equations are valid for:

$$
0.5 \leq \eta_{s} \leq 0.85 \quad 0.2 \leq \frac{W_{s}}{W C} \leq 1
$$




\section{Two stage stochastic model}

Mathematical modelling approach 


\section{Two stage stochastic model}

Mathematical modelling approach

Design of the mechanical vapor compressor

4. Compression work

$W_{s}=\dot{m}_{s}^{\text {sup }} \cdot\left(H_{s}^{\text {sup }}-H_{i, s}^{\text {vapor }}\right) \quad \forall i=I, \forall s \in S$

5. Constraints on temperature and pressure

$$
\begin{array}{ll}
T_{s}^{\text {sup }} \geq T_{i, s}^{\text {mix }} & \forall i=I, \forall s \in S \\
P_{s}^{\text {sup }} \geq P_{i, s}^{\text {vapor }} & \forall i=I, \forall s \in S
\end{array}
$$




\section{Two stage stochastic model}

Mathematical modelling approach

Design specification for ZLD operation

ZLD operation is ensured by the following constraint:

$$
S_{i, s}^{\text {brine }} \geq S^{\text {design }} \quad \forall i=1, \forall s \in S
$$

In this case,

$$
S^{\text {design }}=300 \mathrm{~g} \mathrm{~kg}^{-1} \text { TDS }
$$

The inclusion of this constraint in the model restricts the search space to solutions that meet a minimum salinity requirement for the bine (i.e., brine salinity close to salt saturation conditions)

Lower costs are expected for weaker brine salinity restrictions 


\section{Two stage stochastic model}

Mathematical modelling approach

\section{Stochastic objective function}

The stochastic objective function for the minimization of the expected total annualized cost is given by:

$\min \quad T A C^{E x p}=\sum_{s \in S}\left(\operatorname{prob}_{s}\right) \cdot T A C_{s}=\sum_{s \in S}\left(\operatorname{prob}_{s}\right) \cdot\left(C A P E X+O P E X_{s}\right)$

s.t. all equality and inequality constraints

In which, the distributions of capital investment and operational costs are given by:

$C A P E X=f a c \cdot\left(\frac{C E P C I^{2015}}{C E P C I^{2003}}\right) \cdot\left[\begin{array}{l}\left(C_{P O} \cdot F_{B M} \cdot F_{P}\right)^{\text {evaporator }}+\left(C_{P O} \cdot F_{B M} \cdot F_{P}\right)^{\text {compressor }}+ \\ \left(\sum_{i=1}^{I} C_{P O i} \cdot F_{B M} \cdot F_{P}\right)^{f l a s h}+\left(C_{P O} \cdot F_{B M} \cdot F_{P}\right)^{\text {preheater }}\end{array}\right]$

$O P E X_{s}=C^{\text {electricity }} \cdot W_{s}+C^{\text {steam }} \cdot Q_{s}^{\text {external }}$

\section{Observations:}

0 The resulting formulation was implemented in GAMS (version 24.8.5) and solved with the interior-point local solver IPOPT (with CPLEX sub-solver)

O The CPU time for stochastic optimizations did not exceed $60 \mathrm{~s}$

o The MEE-MVR system should operate at low temperatures and pressures to avoid rusting 


\section{Two stage stochastic model}

Scenarios generation
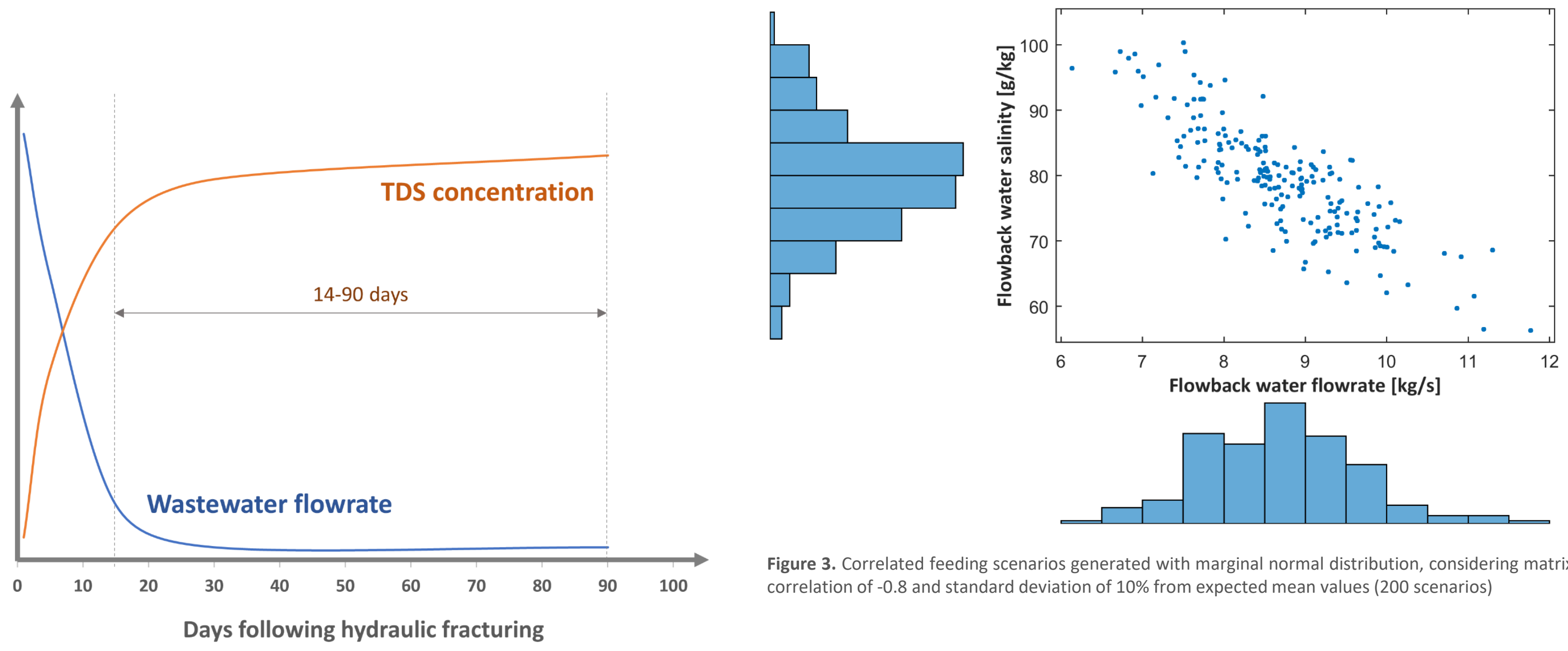

Figure 3. Correlated feeding scenarios generated with marginal normal distribution, considering matrix correlation of -0.8 and standard deviation of $10 \%$ from expected mean values ( 200 scenarios) 


\section{Case study}

Shale gas wastewater desalination

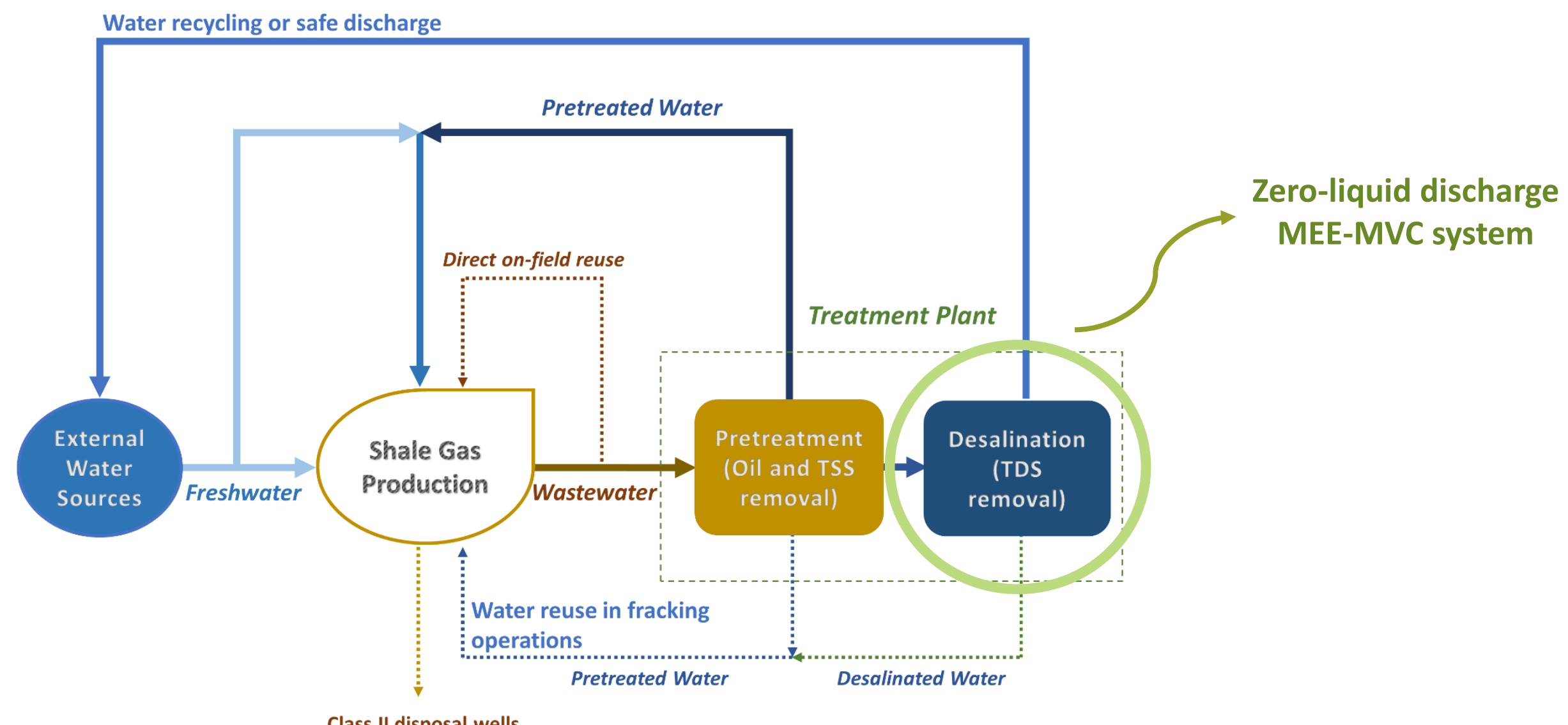

Figure 4. Wastewater management alternatives for shale gas industry 


\section{Case study}

Shale gas wastewater desalination

Table 1. Problem data for the case study regarding the optimal design of MEE-MVR desalination systems under well data uncertainty

\begin{tabular}{|c|c|c|}
\hline \multirow{3}{*}{ Feed water } & Expected mean value for mass flowrate, $\left(\mathrm{kg} \mathrm{s}^{-1}\right)$ & 8.68 \\
\hline & Temperature, $(\stackrel{\circ}{ } \mathrm{C})$ & 25 \\
\hline & Expected mean value for salinity, ( $\mathrm{g} \mathrm{kg}^{-1}$ or k ppm) & 80 \\
\hline \multirow{3}{*}{ Mechanical vapor compressor } & Isentropic efficiency, (\%) & $50-85$ \\
\hline & Heat capacity ratio & 1.33 \\
\hline & Maximum compression ratio & 3 \\
\hline \multirow{3}{*}{$\begin{array}{l}\text { Process specification and } \\
\text { restrictions }\end{array}$} & Brine salinity for ZLD operation, (g kg-1 or k ppm) & 300 \\
\hline & Maximum effect temperature, $(\stackrel{\circ}{ } \mathrm{C})$ & 100 \\
\hline & Maximum effect pressure, (kPa) & 200 \\
\hline \multirow{5}{*}{ Cost data } & Electricity cost ${ }^{a},\left(\mathrm{US} \$(\mathrm{~kW} \text { year })^{-1}\right)$ & 850.51 \\
\hline & Steam cost, (US\$ (kW year) $)^{-1}$ ) & 418.80 \\
\hline & Fractional interest rate per year & 0.1 \\
\hline & Amortization period & 10 \\
\hline & Working hours per year & 8760 \\
\hline
\end{tabular}

Standard deviations: 5,10 and $20 \%$

Matrix correlation: -0.7

a Cost data obtained from Eurostat database (European Commission, 2016) 


\section{Case study}

Shale gas wastewater desalination
Deterministic solution:

TAC: 1055 kUS\$ year $^{-1}$

OPEX: 463 kUS\$ year ${ }^{-1}$

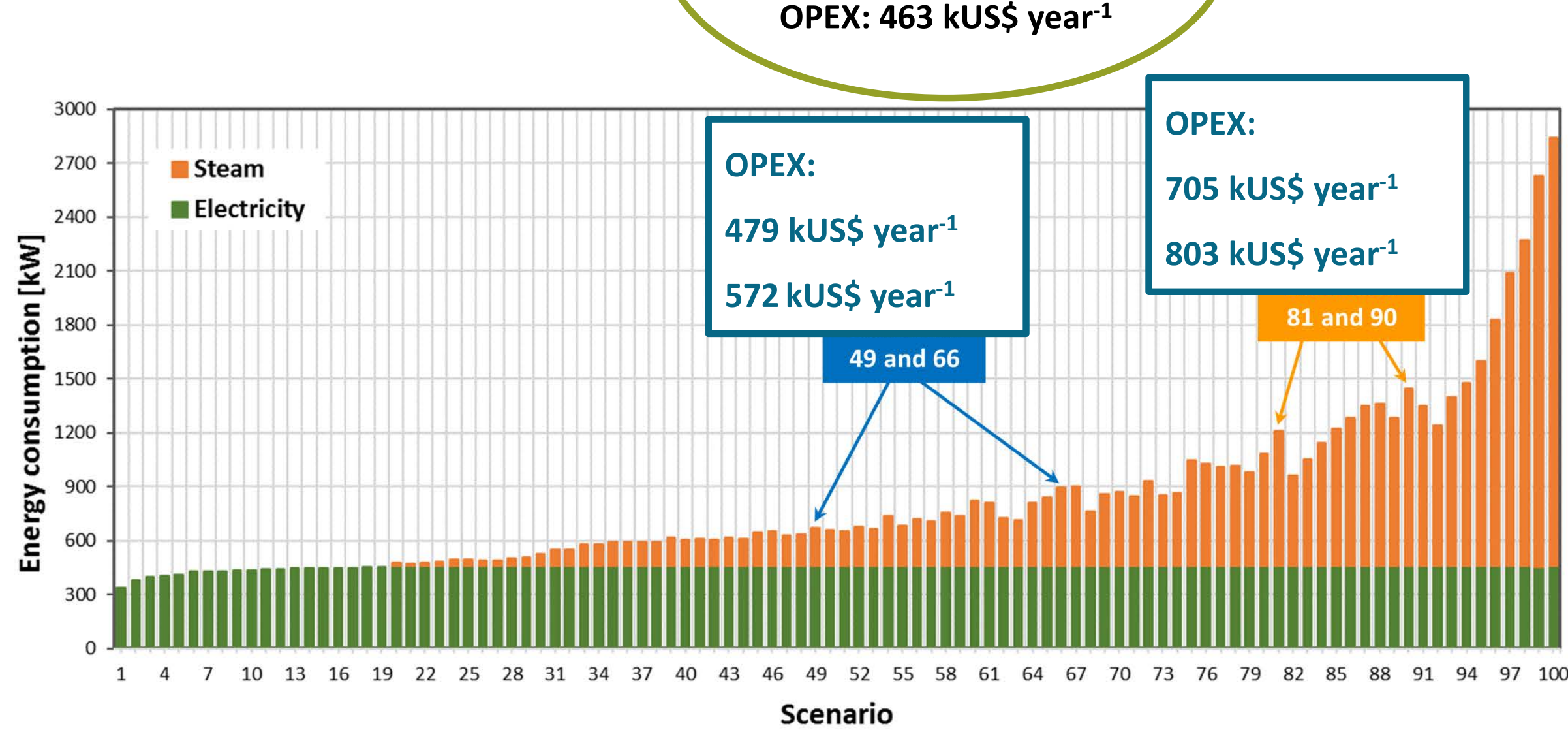

Figure 5. Energy consumption distribution throughout the different feeding scenarios, obtained via stochastic approach with fixed equipment capacities as provided by the deterministic solution
OPEX:

$479 \mathrm{kUS}$ year $^{-1}$

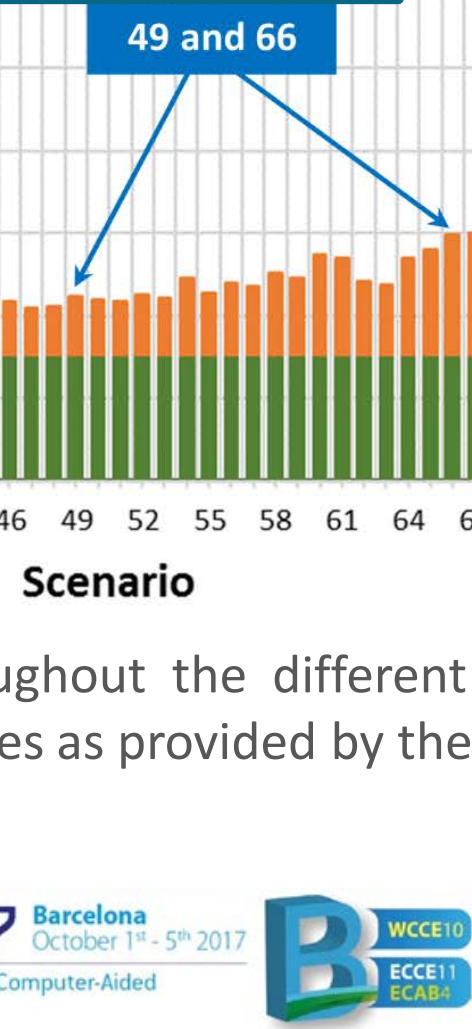

2 kUS\$ year ${ }^{-1}$ 


\section{Case study}

Shale gas wastewater desalination

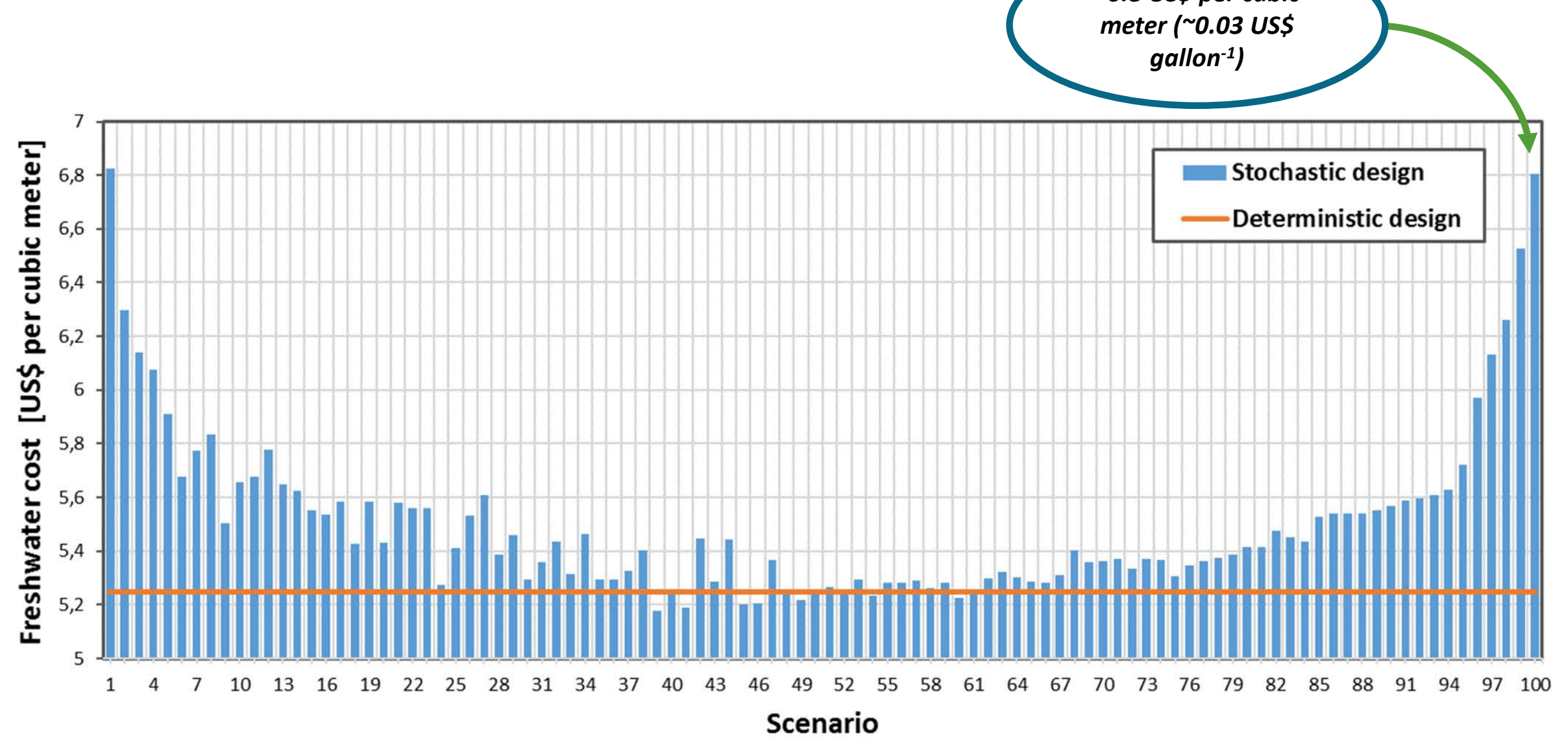

Figure 6. Freshwater cost distribution throughout the different feeding scenarios, obtained via stochastic approach with fixed equipment capacities as provided by the deterministic solution
\%6.8 US\$ per cubic

meter ( 0.03 USS

This value correspond to an increase of $\sim 30 \%$ in comparison with the deterministic solution

.SXT..

SHALEXENVIRONMENT 


\section{Case study}

Shale gas wastewater desalination

\subsection{US\$ per cubic}

meter ( 0.02 USS gallon $^{-1}$ )

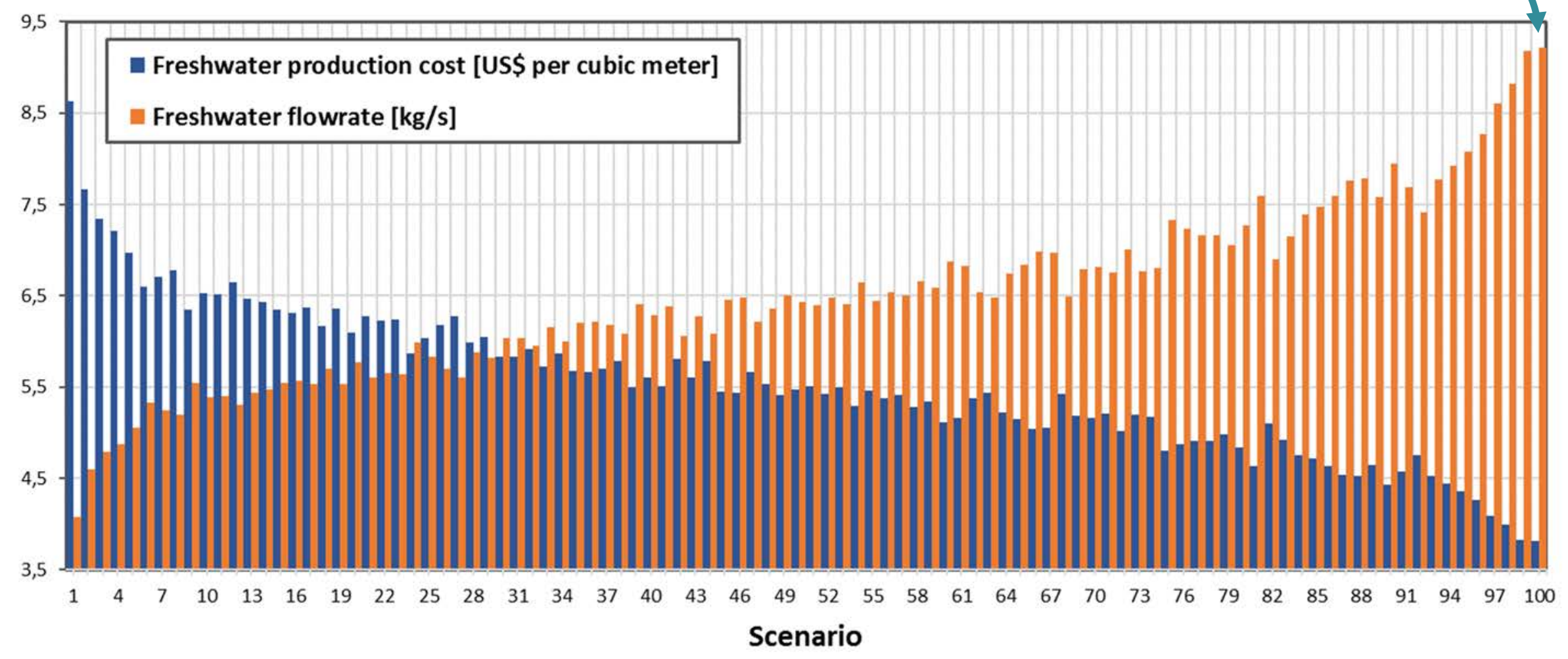

Figure 7. Distributions of freshwater production cost and produced freshwater obtained by the stochastic model throughout the distinct feeding scenarios 


\section{Case study}

Shale gas wastewater desalination
$20 \%$ curve presents $\sim 8 \%$ of probability of exceeding the target cost of 1351 kUS\$ year-1, while this probability is null for the $5 \%$ curve
Higher standard deviations imply riskier decision-making

Figure 8. Cumulative probability curves for the ZLD system economic performance under consideration of correlated uncertain parameters (matrix correlation of 0.7 )

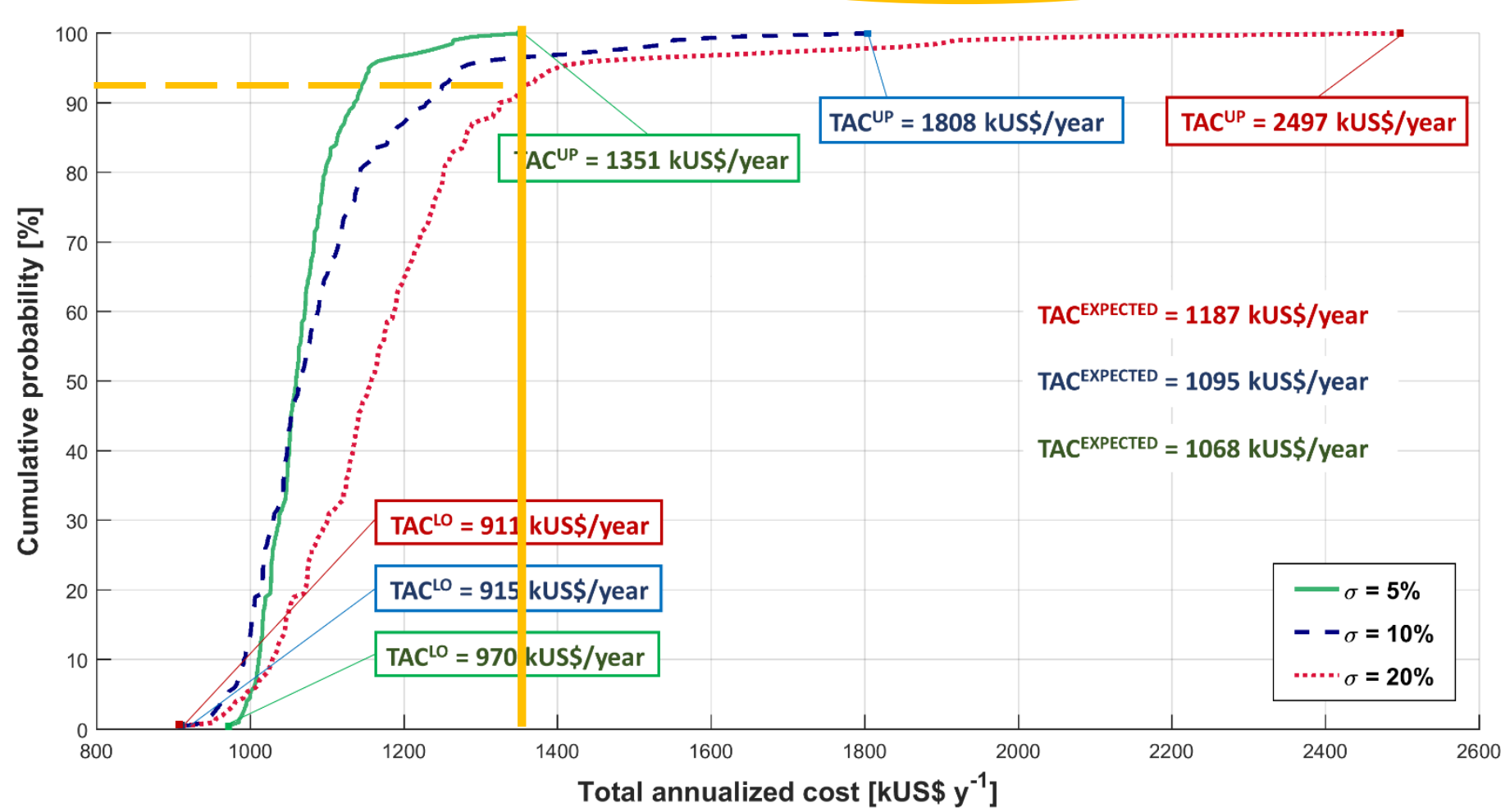




\section{Remarks}

Overview

- A new stochastic multiscenario optimization model is introduced for the robust design of ZLD desalination systems under uncertainty

- Flowback water salinity and flowrate are both considered as uncertain design parameters

- These uncertain parameters are mathematically modelled as a set of correlated scenarios with given probability of occurrence

- The correlated scenarios are generated from a multivariate normal distribution via Monte Carlo sampling technique with a symmetric correlation matrix

- For ensuring the goal of ZLD operation in the uncertain space, we define the discharge brine salinity close to salt saturation condition as a design constraint for all feeding scenarios

- The resulting stochastic multiscenario NLP-based model is implemented in GAMS, and optimized by the minimization of the expected total annualized cost of the desalination process 


\section{Remarks}

- Comparative results between deterministic and stochastic (with fixed deterministic solution) approaches indicate that operational expenses can be prohibitive for some correlated scenarios

- This is because the ZLD process is not able to provide all system flexibility required against feeding variability conditions

- These results highlight the importance of the proposed stochastic model to optimize systems subjected to design parameters uncertainty

- Furthermore, cumulative probability curves show that higher standard deviations for uncertain parameters imply riskier decision-making

- This is a consequence of their increased probability of exceeding a target total annualized cost

- The results obtained can be used to support decision-makers towards the implementation of more robust and reliable ZLD desalination systems in the shale gas industry 


\section{Thank you for your attention!}

\section{Contact}

